\title{
Inelastic vascular prosthesis for proximal aorta increases pulsatile arterial load and causes left ventricular hypertrophy in dogs
}

\author{
Shigeki Morita, MD \\ Toshihide Asou, MD \\ Izumi Kuboyama, $\mathrm{MD}^{\mathrm{a}}$ \\ Yasuhiko Harasawa, $\mathrm{MD}^{\mathrm{b}}$ \\ Kenji Sunagawa, $M D^{\mathrm{b}}$ \\ Hisataka Yasui, MD
}

Objectives: Elastic property of the proximal aorta plays an important role in reducing pulsatile load to the ventricle. When a stiff vascular prosthesis is used for the proximal aorta, the pulsatile load increases. We designed this study to elucidate whether the increase in pulsatile load caused left ventricular hypertrophy.

Methods: We created an ascending aorta-abdominal aorta bypass in 9 dogs with a noncompliant vascular prosthesis. The aortic arch proximal to the left subclavian artery was occluded to direct blood flow into the bypass. Closed chest studies were performed after a median of 139 days (range 45-588) days. We assessed the pulsatile load of the ventricle by calculating characteristic impedance from pressure and flow velocity in the ascending aorta. The left ventricle was weighed, normalized with body weight, and compared with the control group, which had sham operations (7 dogs).

Results: Characteristic impedance of the bypassed dogs was $175 \%$ higher than the control $\left(0.146 \pm 0.056\right.$ vs $\left.0.053 \pm 0.014 \mathrm{~mm} \mathrm{Hg} \cdot \mathrm{s} \cdot \mathrm{mL}^{-1}, P=.009\right)$, which resulted in wider pulse pressure $(57 \pm 11$ vs $25 \pm 11 \mathrm{~mm} \mathrm{Hg}, P<.001)$. No difference was found in arterial resistance, cardiac output, or systolic blood pressure. Left ventricular weight normalized by body weight was significantly heavier in the bypass group $(5.61 \pm 0.75$ vs $4.15 \pm 0.62 \mathrm{~g} / \mathrm{kg}, P=.001)$.

From the Departments of Cardiovascular Surgery ${ }^{\mathrm{a}}$ and Cardiology, ${ }^{\mathrm{b}}$ Faculty of Medicine, Kyushu University, Fukuoka, Japan.

This work was partly supported by grant 60570645 from the Ministry of Education, Science and Culture, Japan.

Received for publication Oct 18, 2001; revisions requested Jan 2, 2002; revisions received Jan 15, 2002; accepted for Feb 16, publication 2002.

Address for reprints: Shigeki Morita, MD, Department of Cardiovascular Surgery, Faculty of Medicine, Kyushu University, 3-1-1 Maidashi, Higashi-ku, Fukuoka 8128582, Japan (E-mail: morita@heart.med. kyushu-u.ac.jp)

J Thorac Cardiovasc Surg 2002;124:768-74

Copyright $(9) 2002$ by The American Association for Thoracic Surgery

$0022-5223 / 2002 \$ 35.00+0 \quad \mathbf{1 2 / 1 / 1 2 4 2 4 4}$

doi: $10.1067 / \mathrm{mtc} .2002 .124244$

Conclusion: Since there was no increase in arterial resistance, we conclude that the increase in pulsatile load was the cause of left ventricular hypertrophy. A stiff vascular prosthesis used for the proximal aorta may cause left ventricular hypertrophy.

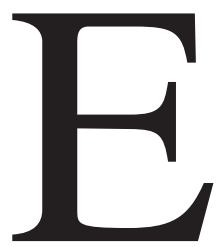

lastic property of the proximal aorta plays an important role in reducing pulsatile load to the ventricle. ${ }^{1-10}$ Pulsatile load increases when the aorta loses elasticity during the aging process. Widened pulse pressure usually seen in the aging population is a manifestation of increased pulsatile load. ${ }^{1,2,5-7}$ Similar changes are observed, when the aorta is replaced or bypassed with stiff vascular prosthesis, ${ }^{10,11}$ because the currently available vascular prostheses are significantly stiffer than the normal aorta. This study was designed to elucidate whether the increase in pulsatile load caused with stiff vascular prosthesis caused left ventricular hypertrophy (LVH) in dogs. We measured aortic impedance, a complete yet concise means to describe ventricular afterload. ${ }^{12}$ An increase in arterial resistance (the static component of aortic impedance) obviously causes LVH, such as in essential hypertension. It has 
not been demonstrated, however, whether LVH is caused by an increase in pulsatile or dynamic component of the aortic impedance.

Increases in aortic impedance were documented in various conditions including aging, ${ }^{1,2}$ hypertension, ${ }^{3}$ coarctation of the aorta, ${ }^{4}$ and after the replacement of the aorta with a vascular prosthesis. ${ }^{11}$ Investigators have stated that the increase in aortic input impedance is injurious to the heart because of an increase in pulsatile load to the ventricle, ${ }^{5}$ thereby increasing systolic and/or pulse pressure, reducing cardiac output, and possibly causing LVH. However, in most of the cases, increases in pulsatile arterial load were accompanied by increased arterial resistance. Thus, it has not been determined how the ventricle responds to the isolated increase in the pulsatile load. Using an ascending aorta-abdominal aorta bypass model, we succeeded in increasing characteristic impedance without altering arterial resistance. ${ }^{10}$ In this model, characteristic impedance increased to more than 2-fold of the control value, resulting in widened pulse pressure, whereas no significant changes observed in static variables such as arterial resistance, mean aortic pressure, or cardiac output. A question arose whether an increase in ventricular afterload caused by high characteristic impedance (increased pulsatile load) would cause LVH.

\section{Methods}

\section{Surgical Preparation}

All animals received humane care in compliance with the "Guide for the Care and Use of Laboratory Animals" prepared by the institute of Laboratory Animal Resources, National Research Council, and published by the National Academy Press, revised 1996. This experiment was reviewed by the Committee of the Ethics on Animal Experiment in Faculty of Medicine, Kyushu University and carried out under the control of the Guideline for Animal Experiment in Faculty of Medicine, Kyushu University and The Law (No. 105) and Notification (No. 6) of the Government.

In 9 adult mongrel dogs $(18.2 \pm 2.2 \mathrm{~kg})$, a bypass graft between the ascending aorta to the abdominal aorta was performed (Figure 1 ), according to the method for thoracoabdominal aneurysm reported by Carpentier and his colleagues. ${ }^{13}$ Originally they occluded the descending aorta distal to the left subclavian artery. In our model, we occluded the aortic arch between the brachiocephalic artery and the left subclavian artery to keep the descending thoracic aorta patent; blood flowed through the bypass graft, then into the descending thoracic aorta with a reversed flow direction, and eventually reached to the left subclavian artery.

Pentobarbital (30 mg/kg administered intravenously) was given and an endotracheal tube was inserted and connected to a volume respirator (Harvard model NSH-348H; Harvard Apparatus, Inc, Holliston, Mass). The chest was opened by means of a median sternotomy with aseptic technique. The pericardium was longitudinally opened and the aortic arch and its two branches (the brachiocephalic artery and the left subclavian artery) were dissected. A partial occluding clamp was applied to the ascending

\section{BYPASS}

\section{CONTROL}
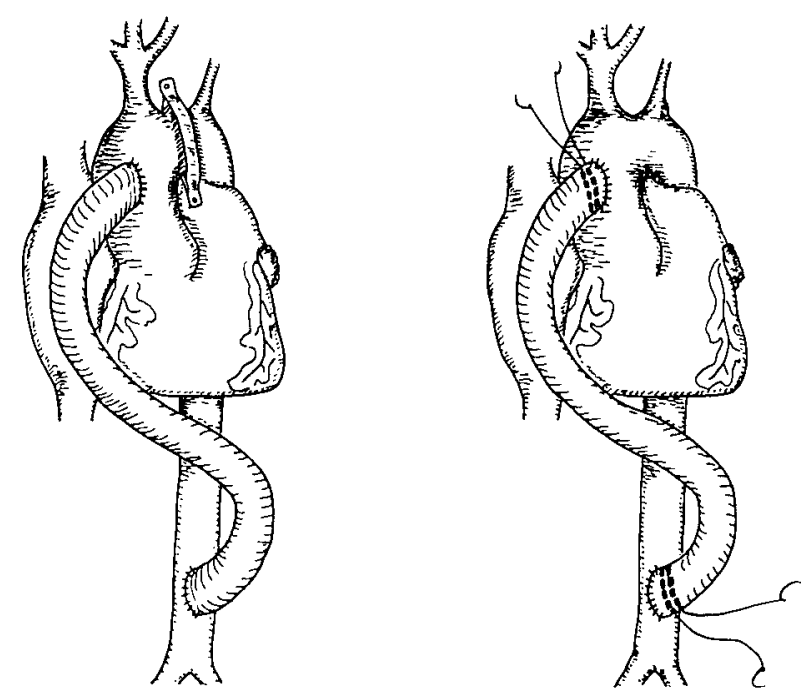

Figure 1. Surgical preparations are shown for the dogs with bypass (left panel) and control (right panel). The bypass was constructed from the ascending aorta to the abdominal aorta. The aortic arch was occluded with an implantable aortic clamp between the brachiocephalic artery and the left subclavian artery in the bypass group. The blood flowed through the bypass graft and retrogradely flowed into the descending thoracic aorta and to the left subclavian artery (left panel). In the control group, the same operation was performed as in the bypass group except for not occluding the aortic arch and the bypass graft being suture ligated at the both ends so that the blood flowed normally (right panel).

aorta and a knitted Dacron vascular prosthesis, 12-mm inner diameter and 40-cm long, was anastomosed. After completion of the anastomosis, a midline laparotomy was performed and the distal end of the vascular prosthesis was brought through a stab wound at the diaphragm, and the prosthesis was anastomosed to the abdominal aorta just distal to the renal arteries. The aortic arch was occluded between the brachiocephalic and the left subclavian artery by an implantable aortic clamp. The incision was closed, and a chest tube was left in the pleural cavity. Two doses of antibiotics (cephalothin $250 \mathrm{mg}$ administered intravenously $\times 2$ ) were given before and after the operation. The chest tube was removed 2 to 4 hours after the operation.

As a control, same procedure was performed in 7 dogs except that both ends of the vascular prosthesis was suture ligated and the aortic arch was left patent (Figure 1). In the control dogs there was no flow in the bypass graft and blood was flowing into the native arterial system with the normal direction.

\section{Instrumentation}

After the operation (a median of 163 days, ranging from 33 to 302 days in the control dogs and a median of 139 days, ranging from 45 to 588 days in the bypassed dogs), the dogs underwent closedchest hemodynamic measurements. The interval between the day 
of the operation and the day of study was randomly selected to examine whether there was a time-dependent change in ventricular weight. $\alpha$-Chlolarose $(45 \mathrm{mg} / \mathrm{kg})$ and urethane $(450 \mathrm{mg} / \mathrm{kg})$ were given intravenously for anesthesia. We maintained spontaneous respiration to prevent an endotracheal intubation. A thermodilution catheter (Edwards Laboratories, Inc, Santa Ana, Calif) was inserted either from the right external jugular vein or from the right femoral vein and the tip was placed into the pulmonary artery. A multisensor pressure and flow-velocity catheter (model VPC684D; Millar Instruments, Inc, Houston, Tex) was inserted from the right carotid artery. This catheter had 2 pressure sensors and a velocity sensor. The distance between the 2 pressure sensors was $5 \mathrm{~cm}$ and the velocity sensor was at the same location of the proximal pressure sensor. Using this catheter, we simultaneously measured left ventricular pressure and aortic flow velocity and pressure at the ascending aorta. The proximal pressure sensor was positioned just above the aortic valve by monitoring the pressure tracing. The catheter was prewarmed at least 1 hour before the procedure to prevent zero drift. A flow-directed pacing catheter (model 97-1205F; Edwards Laboratories) was inserted from the right femoral vein into the right atrium. All data were recorded on an 8-channel chart recorder (NEC Sanei-140, Tokyo, Japan) and on a magnetic tape (TEAC-R81, Musashino, Japan). Data were also online digitized (200 samples per second, 12 bits) by a personal computer (NEC PC-9801E, Tokyo, Japan) and stored in floppy disks for offline analysis.

\section{Measurements}

First, the heart was allowed to beat at its own rhythm. Cardiac output was measured by the thermodilution catheter. Aortic flow velocity was calibrated by the cardiac output to obtain instantaneous volumetric flow. Heart rate, systolic aortic pressures, diastolic aortic pressure, mean aortic pressure, left ventricular pressure, left ventricular end-diastolic pressure, first derivative of left ventricular pressure, instantaneous aortic flow, and mean aortic flow (cardiac output) were recorded. Arterial resistance was calculated as mean aortic pressure divided by cardiac output.

We next measured high-resolution aortic impedance by use of the random excitation technique of Taylor. ${ }^{14} \mathrm{We}$ reported the method in detail, previously. ${ }^{10}$ In brief, the heart was paced at random by the atrial pacing electrodes. Pressure and flow data of the ascending aorta were recorded for 40.96 seconds (213 samples). Systolic aortic pressure fluctuated from approximately 80 to $160 \mathrm{~mm} \mathrm{Hg}$ during the random excitation of the heart. We determined impedance spectrum over a frequency range of $0.098 \mathrm{~Hz}$ through $20 \mathrm{~Hz}$ with a resolution of $0.098 \mathrm{~Hz}$. The impedance spectrum was plotted on logarithmic scales of frequency and modules (Bode plot). Characteristic impedance was calculated by averaging impedance moduli between $5 \mathrm{~Hz}$ and $15 \mathrm{~Hz}$. Arterial compliance (C) was calculated as

$$
C=1 /(2 \pi \cdot F c h \cdot R c)
$$

where Rc is characteristic impedance and Fch represents corner frequency, at which the linear regression line obtained from impedance moduli between $0.5 \mathrm{~Hz}$ and $1.5 \mathrm{~Hz}$ reaches Rc. ${ }^{15}$ This method of calculating arterial compliance is analogous to regressing impedance spectrum to the 3 -element windkessel model. ${ }^{16,17}$
From the data with regular-own rhythm, pulsatile work was calculated as

$$
0.5 \Sigma P_{n} F_{n} \cos \phi_{n}{ }^{12}
$$

where $\mathrm{P}_{\mathrm{n}}, \mathrm{F}_{\mathrm{n}}$, and $\phi_{\mathrm{n}}$ are pressure modulus, flow modulus, and impedance phase at the nth harmonics. Pulsatile work was presented as per-beat basis with a unit of millimeters of mercury times cubic centimeters. Mean work was calculated as a product of mean aortic pressure and flow (stroke volume). Total work was given as a sum of pulsatile work and mean work.

After the hemodynamic measurements, the chest was opened and the dog was killed with an intravenous injection of pentobarbital and potassium chloride. The heart was removed immediately, and the both atria and fibrous structures (valves and chordae) were carefully detached from the ventricles. The right ventricular free wall was removed and weighed. The left ventricular weight including the septum was measured, and its ratios to the body weight (LV/BW) and to the right ventricular free wall weight (LV/RV) were calculated.

\section{Statistics}

All data are presented as mean $\pm \mathrm{SD}$. A $t$ test was performed to detect the difference between groups. Correlation coefficients between the 2 variables were obtained to determine the relation between the weight of left ventricular mass and the interval in days between the operation and the study.

\section{Results}

All 9 dogs with bypass surgery had measurements in pressures and cardiac output. Aortic input impedance was not available in 3 dogs; 2 had ventricular fibrillation during the random pacing of the heart, and in 1 dog the velocity catheter was not available. Thus, impedance data were available in 6 dogs. A complete set of measurements was obtained in all control dogs. Hemodynamic variables are summarized in Table 1. Representative pressure and flow tracings of a control dog and a dog with bypass are shown in Figure 2. As expected, pulse pressure was significantly larger in the dogs with bypass (128\% larger than the control). Although systolic pressure in a representative dog was higher than in a control dog (Figure 2), pooled data showed no difference in systolic arterial pressure between the 2 groups (Table 1). The increase in pulse pressure was the result of the low diastolic pressure $(17.5 \%$ lower than the control). Mean arterial pressure of the bypass group was $12 \%$ lower than that of the control group. No sizable difference in left ventricular performance was determined by cardiac output, left ventricular end-diastolic pressure, or the maximum value of the first derivative of the left ventricular pressure. There also was no difference in arterial resistance.

Representative impedance spectra are shown in Figure 3. In a control dog, the first minimum appeared at $4 \mathrm{~Hz}$, whereas in a dog with bypass, the first minimum appeared at $2 \mathrm{~Hz}$ followed by a large maximum at $4 \mathrm{~Hz}$ and the impedance was persistently elevated at higher frequencies. 

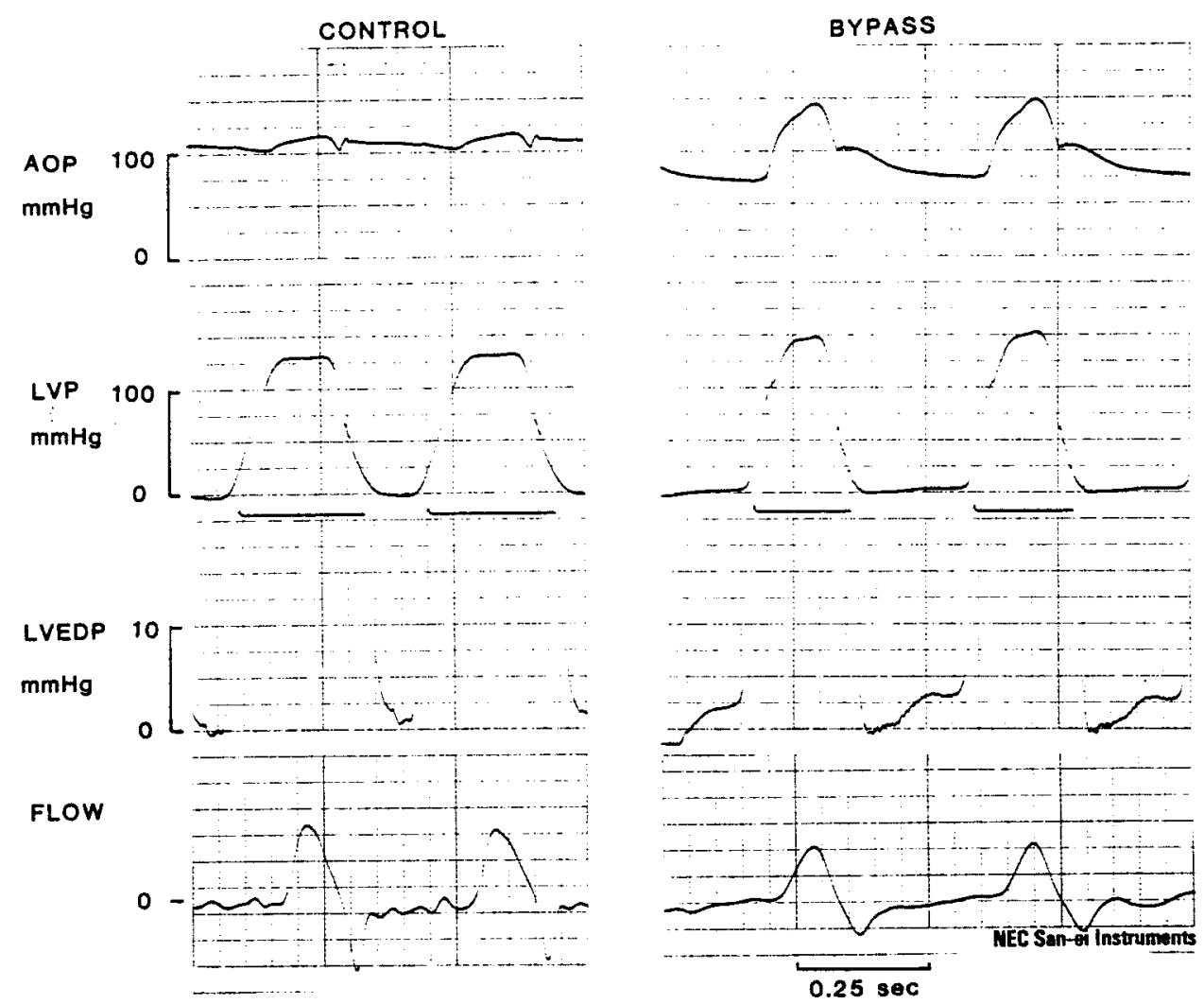

Figure 2. Representative time domain pressure and flow tracings are shown. Since the flow tracings are obtained by velocity sensor and were calibrated later with cardiac output obtained by thermodilution catheter, the scale and unit of the flow signals are not shown in the figure. AOP, Aortic pressure; LVP, left ventricular pressure; LVEDP, left ventricular end-diastolic pressure.

TABLE 1. Hemodynamic variables

\begin{tabular}{|c|c|c|c|}
\hline & Control & Bypass & $P$ value \\
\hline $\mathrm{HR}$ (L/min) & $163 \pm 27$ & $161 \pm 28$ & $>.2$ \\
\hline $\mathrm{Pm}(\mathrm{mm} \mathrm{Hg})$ & $137 \pm 18$ & $116 \pm 16$ & .03 \\
\hline Ps (mm Hg) & $149 \pm 22$ & $156 \pm 16$ & $>.2$ \\
\hline $\mathrm{Pd}(\mathrm{mm} \mathrm{Hg})$ & $125 \pm 14$ & $99 \pm 17$ & .008 \\
\hline $\mathrm{Pp}(\mathrm{mm} \mathrm{Hg})$ & $25 \pm 11$ & $57 \pm 12$ & .001 \\
\hline $\mathrm{CO}(\mathrm{L} / \mathrm{min})$ & $2.59 \pm 1.48$ & $2.21 \pm 0.89$ & .2 \\
\hline SV (mL) & $14.6 \pm 8.2$ & $14.2 \pm 6.4$ & .2 \\
\hline LVEDP $(\mathrm{mm} \mathrm{Hg})$ & $3.9 \pm 2.3$ & $3.2 \pm 2.3$ & $>.2$ \\
\hline $\mathrm{dP} / \mathrm{dtmax}(\mathrm{mm} \mathrm{Hg} / \mathrm{s})$ & $3041 \pm 923$ & $3071 \pm 1191$ & $>.2$ \\
\hline $\mathrm{R}\left(\mathrm{mm} \mathrm{Hg} \cdot \mathrm{s} \cdot \mathrm{mL}^{-1}\right)$ & $4.66 \pm 2.64$ & $3.60 \pm 1.44$ & $>.2$ \\
\hline Mean work $\left(\mathrm{mm} \mathrm{Hg} \cdot \mathrm{cm}^{3} \cdot\right.$ beat $\left.^{-1}\right)$ & $1956 \pm 1224$ & $1701 \pm 949$ & $>.2$ \\
\hline Pulsatile work $\left(\mathrm{mm} \mathrm{Hg} \cdot \mathrm{cm}^{3} \cdot\right.$ beat $\left.^{-1}\right)$ & $157 \pm 199$ & $424 \pm 199$ & .019 \\
\hline Total work $\left(\mathrm{mm} \mathrm{Hg} \cdot \mathrm{cm}^{3} \cdot\right.$ beat $\left.^{-1}\right)$ & $2113 \pm 1413$ & $2125 \pm 1107$ & $>.2$ \\
\hline Pulsatile/total work (\%) & $6.2 \pm 3.3$ & $20.7 \pm 4.5$ & $<.001$ \\
\hline
\end{tabular}

$H R$, Heart rate; $P m$, mean aortic pressure; $P s$, systolic aortic pressure; $P d$, diastolic aortic pressure; $P p$, pulse pressure; $C O$, cardiac output; $S V$, stroke volume; $L V E D P$, left ventricular end-diastolic pressure; $d P / d t m a x$, maximum value of the first derivative of left ventricular pressure; $R$, arterial resistance.

Figure 4 summarizes the values of parameters obtained from impedance spectra. Characteristic impedance of the bypass group was $0.146 \pm 0.056 \mathrm{~mm} \mathrm{Hg} \cdot \mathrm{s} \cdot \mathrm{mL}^{-1}$, which was $175 \%$ higher than the control value of $0.053 \pm 0.014$ $\mathrm{mm} \mathrm{Hg} \cdot \mathrm{s} \cdot \mathrm{mL}^{-1}(P=.009)$. No difference was found in arterial compliance (the control group, $0.483 \pm 0.103$ $\mathrm{mL} / \mathrm{mm} \mathrm{Hg}$ vs the bypass group, $0.488 \pm 0.189 \mathrm{~mL} / \mathrm{mm}$ $\mathrm{Hg}, P>0.2$ ) nor in arerial resistance (the control group 
CONTROL
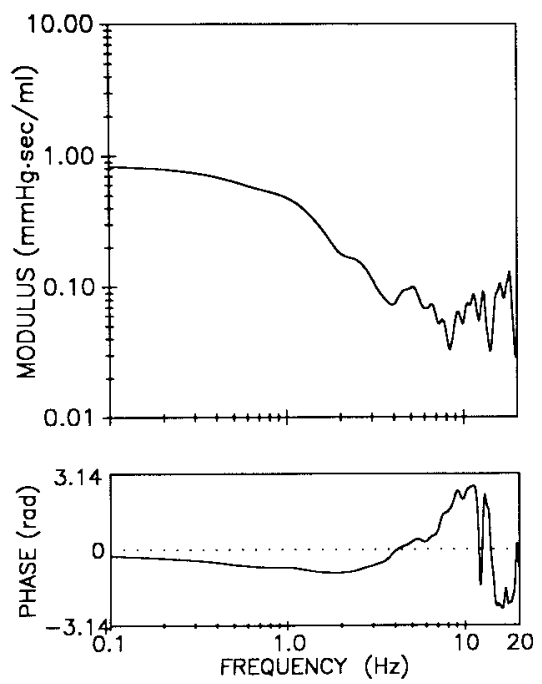

BYPASS
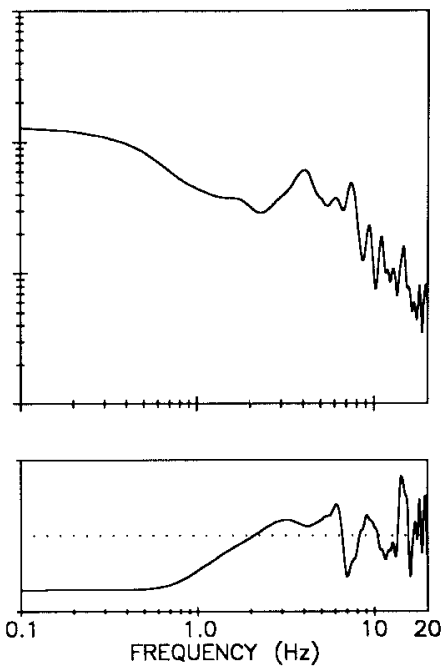

Figure 3. Representative aortic input impedance spectra of a control dog (left panel) and a dog with a bypass (right panel) are shown. In the control dog, the first minima appeared at about $4 \mathrm{~Hz}$. In a dogs with bypass the first minima was at $2 \mathrm{~Hz}$ and it was followed by large maxima, which was seen at $4 \mathrm{~Hz}$. Impedance was persistently elevated at higher frequency range.

RESISTANCE

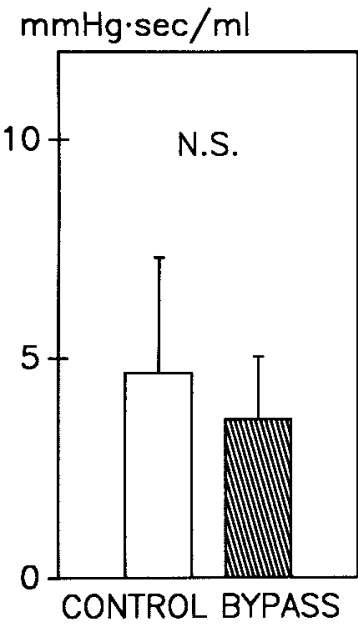

COMPLIANCE

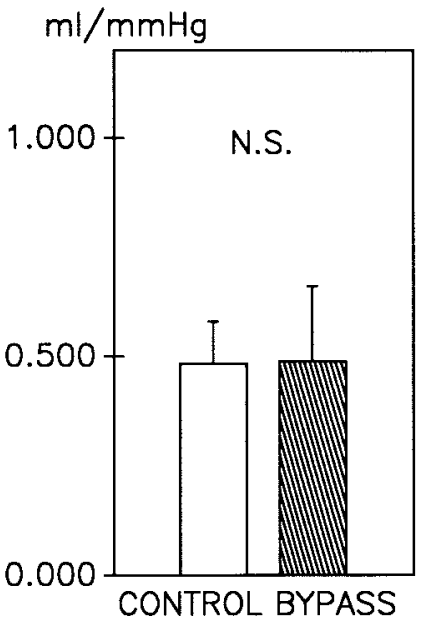

CHARACTERISTIC

IMPEDANCE

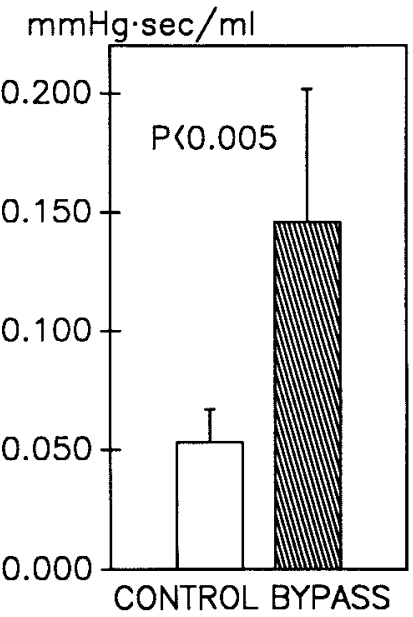

Figure 4. Comparison of resistance (left panel), arterial compliance (middle panel), and characteristic impedance (right panel) between the control and bypass group. Characteristic impedance was significantly higher in the dogs with bypass, whereas no significant differences in resistance and compliance were observed between the 2 groups.

$4.66 \pm 2.64 \mathrm{~mm} \mathrm{Hg} \cdot \mathrm{s} \cdot \mathrm{mL}^{-1}$ vs $3.60 \pm 1.44 \mathrm{~mm}$ $\left.\mathrm{Hg} \cdot \mathrm{s} \cdot \mathrm{mL}^{-1}, P>.2\right)$. There was no difference in total work, but pulsatile work was significantly higher in the bypassed animals, and accordingly the fraction of pulsatile work to the total work was larger (Table 1).

The left ventricle of the bypass group was heavier than that of the control group (Table 2). In the bypass group, the ratio of left ventricle to body weight was $35 \%$ larger than in the control group. There was no significant difference in body weight at the date of graft implantation and at the termination of the study (bypass group, $18.2 \pm 2.2 \mathrm{~kg}$ at the date of implantation vs $18.8 \pm 3.7 \mathrm{~kg}$ at the date of termi- 
nation; control group, $20.5 \pm 2.9 \mathrm{~kg}$ vs $21.6 \pm 2.5 \mathrm{~kg}$ ). The ratio of the left ventricle to right ventricle in the bypass group was 19\% larger than in the control dogs.

The correlation coefficient between the normalized left ventricular weight of the bypass group and the interval after surgery (a median of 139 days, ranging from 45 to 588 days in the 9 bypassed dogs) was low $(r=0.275, P=.460)$, which indicated that there was no time-dependent increase in the degree of LVH after postoperative day 45.

\section{Discussion}

The major finding of the present study was that stiff vasular prosthesis increased pulsatile load (characteristic impedance), which resulted in LVH. Although it has been suggested that pulsatile load may cause $\mathrm{LVH}$, to the best of our knowledge, this is the first experimental study to create LVH by an isolated increase in pulsatile arterial load. Since the stiff aortic system increases pulsatile arterial load, it is indicative that replacement of proximal aorta with an inelastic vascular prosthesis may cause LVH after surgery. Few studies, however, examined the relation between the use of vascular prosthesis and pulsatile arterial load. ${ }^{10,12,18,19}$ No previous study has shown the link among arterial impedance, vascular prosthesis, and the development of LVH.

The attempts to analyze arterial pulsatile load have a long history, as old as the windkessel model proposed by Frank $^{20}$ in 1899. Precise measurement of pulsatile arterial load had to wait until the frequency domain approach was introduced. Pulsatile arterial load, measured as a frequency term of aortic input impedance, has been extensively measured in human subjects ${ }^{2,3}$ and in animals. . $^{4,8,10,14-16}$ It has been known in aged populations that (1) there are increases in characteristic impedance and arterial resistance,(2) the degree of increase is larger in characteristic impedance, and (3) the aged population shows a mild degree of LVH., ${ }^{3,21}$ On the basis of these observations, it has been hypothesized that an increase in pulsatile arterial load would result in LVH. The hypothesis, however, has never been tested.

Our bypass model is unique in creating an isolated increase in characteristic impedance. Other factors that would cause LVH were either unaltered (arterial resistance, systolic blood pressure, cardiac output, left ventricular enddiastolic pressure) or decreased (mean arterial pressure). The elevated characteristic impedance was the only responsible factor for causing LVH in our model. The amount of increase in characteristic impedance seen in our present study (175\% increase) was comparable with the increase seen in aged populations ( $137 \%$ increase). ${ }^{3}$ The degree of hypertrophy developed in our study (19\% increase in LV/RV ratio) was also comparable with LVH seen in aged populations (22\% increase in left ventricular wall thickness). ${ }^{21}$ An increase in resistance caused by aging was relatively small (37\% increase) compared with an increase in characteristic impedance. ${ }^{3}$ The similarities seen between
TABLE 2. Comparison of ventricular weights

\begin{tabular}{lccc}
\hline & Control & Bypass & $P$ value \\
\hline BW $(\mathrm{kg})$ & $21.6 \pm 2.5$ & $18.8 \pm 3.7$ & .116 \\
LV $(\mathrm{g})$ & $88.7 \pm 7.0$ & $103.8 \pm 17.0$ & .034 \\
RV $(\mathrm{g})$ & $30.9 \pm 3.5$ & $30.6 \pm 7.3$ & .02 \\
LV/BW $(\mathrm{g} / \mathrm{kg})$ & $4.15 \pm 0.62$ & $5.61 \pm 0.75$ & $<.001$ \\
LV/RV & $2.91 \pm 0.42$ & $3.46 \pm 0.41$ & .020 \\
\hline
\end{tabular}

$B W$, Body weight; $L V$, left ventricular weight including septum; $R V$, right ventricular free wall weight.

our experimental result and in aged populations suggest that elevated pulsatile arterial load was one of the causes of LVH.

Why does an increase in characteristic impedance cause LVH? Protein synthesis leading to ventricular hypertrophy is triggered by an increase in ventricular wall stress. ${ }^{22}$ Since there was no increase in systolic aortic pressure and left ventricular end-diastolic pressure, determinants of ventricular wall stress (ventricular diameter and pressure) were not supposed to be increased in the dog with bypass graft. Kim and associates ${ }^{11}$ showed that although there was no increase in systolic pressure at rest in patients with aortic interposed grafts, systolic pressure immediately increased after exercise, and the increase in sytolic pressure was accompanied by the increase in the fraction of pulsatile load. Because of the technical limitation in our study, we had to study the animals under general anesthesia. Despite the limitation in our study, it is suggestive from the study by Kim and his colleagues, ${ }^{11}$ showing higher systolic pressure in patients with increased characteristic impedance, that systolic blood pressure of our animals had been elevated when the animals had been awake, especially during exercise. It has been reported that elevation in systolic blood pressure with the presence of increased characteristic impedance is detrimental in terms of left ventricular energetics and efficiency. ${ }^{19} \mathrm{~A}$ combination of these factors might have contributed to the development of LVH in our animals.

Although it has been considered that elevated pulsatile load has a negative effect on cardiac output, ${ }^{5}$ we could not observe any differences in cardiac output between the 2 groups. The result was consistent with our previous open chest study ${ }^{10}$ and the study of Kelly and associates, ${ }^{19}$ which used almost identical models. In both studies, no difference in cardiac output was observed with more than 2-fold increase in characteristic impedance. Sunagawa and cowork$\mathrm{ers}^{23}$ showed that relative changes of stroke volume by doubling or halving resistance, compliance, and characteristic impedance were $100 \%, 12 \%$, and $4 \%$, respectively. Their results implied that stroke volume was sensitive to the change in resistance but less sensitive to compliance and least sensitive to characteristic impedance. The cardiac output in patients with aortic interposed grafts was not reduced despite a significant increase in characteristic impedance 
compared with the control group. ${ }^{11}$ All these studies were in accordance with our result, that is, increased characteristic impedance had least effect on cardiac output or on stroke volume.

The limitations of the study should be noted. First, since we were unable to follow characteristic impedance serially after the surgery, we do not know how long and to what extent the ventricle was loaded with high characteristic impedance. The animals were not studied during the early postoperative period. We cannot rule out the possibility of transient increase in arterial resistance during this early postoperative period. It was unlikely, though, to expect an alteration in characteristic impedance during the postoperative period, because neither diameter nor distensibility of the vascular prosthesis should alter. In fact, in our previous open chest study using the same bypass model, characteristic impedance increased $155 \%$ immediately after the operation, ${ }^{10}$ which was comparable with observations in the present study ( $175 \%$ increase in characteristic impedance).

Second, in our model, the length of the graft $(40 \mathrm{~cm})$ was longer than is typically used in aortic surgery. In addition, wave reflection from the clamp placed at the aortic arch is expected, which might as well increase the pulsatile load. Although we could not separate the effect of wave reflection $^{24}$ and the effect of inelastic property of the vascular prosthesis, a comparable increase in characteristic impedance (63\% increase) was observed in patients who had an aortic interposition graft. ${ }^{11}$ In these patients, the average length of the graft was $4.5 \mathrm{~cm}$ and the site of interposition was the descending aorta. Characteristic impedance would be larger if the length of the graft was longer and the site of interposition was closer to the heart. We thus assume that patients with total arch replacement or those who underwent aortic root replacement would show significant increase in characteristic impedance. Further study is warranted to examine whether the patients with interposed aortic grafts are prone to develop $\mathrm{LVH}$ after the operation.

In conclusion, LVH developed in dogs with elevated pulsatile arterial load. Since there was no increase in static arterial load, we concluded that an increase in pulsatile arterial load was the cause of LVH.

We appreciate Mr Shinobu Gyoutoku and Mrs Yoshiko Tsukuda for their superb technical assistance. We also appreciate Dr Noriya Taki, the director of The Institute for Medical Statistics, as a consultant statistician.

\section{References}

1. Yin FCP. Aging and vascular impedance: In: Yin FCP, editor: Ventricular/vascular coupling: clinical, physiological, and engineering aspects. New York:, Springer-Verlag; 1987. p. 115-39.
2. Nichols WW, O'Rourke MF, Avolio AP, Yaginuma T, Murgo JP, Pepine CJ, et al. Effects of age on ventricular-vascular coupling. Am J Cardiol. 1985;55:1179-84.

3. O'Rourke MF. Arterial hemodynamics in hypertension. Circ Res. 1970;26(Suppl 2):II-123-33.

4. O'Rourke MF, Cartmill TB. Influence of aortic coarctation on pulsatile hemodynamics in the proximal aorta. Circulation. 1971;44:28192.

5. O'Rourke MF. Steady and pulsatile energy losses in the systemic circulation under normal conditions and in simulated arterial disease. Cardiovasc Res. 1967;1:313-26.

6. Randall OS, van den Bos GC, Westerhof N. Systemic compliance: does it play a role in the genesis of essential hypertension? Cardiovasc Res. 1984;18:455-62.

7. Salisbury PF, Cross CE, Rieben PA. Ventricular performance modified by elastic properties of outflow system. Circ Res. 1962;11:319-28.

8. Yin FCP, Spurgeon HA, Weisfeldt ML, Lakata EG. Mechanical properties of myocardium from hypertrophied rat hearts: a comparison between hypertrophy induced by senescence and by aortic banding. Circ Res. 1980;46:292-300.

9. Safar ME, Toto-Moukouo JJ, Bouthier JA, Asmar RE, Levenson JA, Simon AC, et al. Arterial dynamics, cardiac hypertrophy, and antihypertensive treatment. Circulation. 1987;75(Suppl):I-156-61 .

10. Morita S, Kuboyama I, Asou T, Tokunaga K, Nosé Y, Nakamura M, et al. The effect of extra-anatomic bypass on aortic input impedance studied in open chest dogs: Should the vascular prosthesis be compliant to unload the left ventricle? J Thorac Cardiovasc Surg. 1991;102: $774-83$.

11. Kim SY, Hinkamp TJ, Jacobs WR, Lichtenberg RC, Posniak H, Pifarré R. Effect of an inelastic aortic synthetic vascular graft on exercise hemodynamics. Ann Thorac Surg. 1995;59:981-9.

12. Milnor WR. Arterial impedance as ventricular afterload. Circ Res. 1975;26:565-70.

13. Carpentier A, Deloche A, Fabiani JN, Chauvaud S, Relland J, Nottin $\mathrm{R}$, et al. New surgical approach to aortic dissection: flow reversal and thromboexclusion. J Thorac Cardiovasc Surg. 1981;81:659-68.

14. Taylor MG. Use of random excitation and spectral analysis in the study of frequency-dependent parameters of the cardiovascular system. Circ Res. 1966;18:585-95.

15. Harasawa Y, Sunagawa K, Nakamura M, Watanabe Y, Nosé Y. Evaluation of mechanical property of systemic arterial system by ultra-high resolution aortic input impedance over four decades [abstract]. Jpn Circ J. 1985;49:895.

16. Latson TW, Hunter WC, Katoh N, Sagawa K. Effect of nitroglycerine on aortic impedance, diameter, and pulse-wave velocity. Circ Res. 1988;62:884-90.

17. Westerhof N, Elzinga G, Sipkema P. An artificial arterial system for pumping hearts. J Appl Physiol. 1971;31:776-81.

18. Mitsui T, Maeta H, Fukuda I, Ijima H, Okamura K, Sakai A, et al. Left ventricular hypertrophy due to aortic bypass grafting with a long prosthesis. J Cardiovasc Surg (Torino). 1986;27:201-6.

19. Kelly RP, Tunin R, Kass DA. Effect of reduced aortic compliance on cardiac efficiency and contractile function of in situ canine left ventricle. Circ Res. 1992;71:490-502.

20. Frank O: Die Grundform des Arteriellen Puls. Z Biol. 1899;37:483526.

21. Gerstenblith G, Frederiksen J, Yin FCP, Fortuin NJ, Lakatta EG, Weisfeldt ML. Echocardiographic assessment of a normal adult aging population. Circulation. 1977;56:273-8.

22. Hunter JJ, Grace A, Chien KR. Molecular and cellular biology of cardiac hypertrophy and failure. In: Chien KR, Breslow JL, Leiden JM, Rosenberg RD, Seidman CE, editors. Molecular basis of cardiovascular disease. Philadelphia: WB Saunders; 1999. p. 211-50.

23. Sunagawa K, Maughan WL, Sagawa K. Stroke volume effect of changing arterial input impedance over selected frequency ranges. Am J Physiol. 1985;248:H477-84.

24. Westerhof N, Sipkema P, Van den Bos GC, Elzinga G. Forward and backward waves in the arterial system. Cardiovasc Res. 1972;6:64856. 